\title{
Investigation of Optimal Afferent Feedback Modality for Inducing Neural Plasticity with A Self-Paced Brain-Computer Interface
}

\author{
Mads Jochumsen ${ }^{1}$, Sylvain Cremoux ${ }^{2}$, Lucien Robinault ${ }^{2} \oplus$, Jimmy Lauber ${ }^{2}$, \\ Juan Carlos Arceo ${ }^{2}$, , Muhammad Samran Navid ${ }^{3,4}{ }^{(D}$, Rasmus Wiberg Nedergaard ${ }^{3,4}$, \\ Usman Rashid ${ }^{5}$ (D) Heidi Haavik ${ }^{4}$ and Imran Khan Niazi $1,4,5, *$ (D) \\ 1 SMI, Department of Health Science and Technology, Aalborg University, Aalborg 9220, Denmark; \\ mj@hst.aau.dk \\ 2 LAMIH, UMR CNRS 8201, Université Polytechnique des Hauts de France, Valenciennes 59313, France; \\ sylvain.cremoux@uphf.fr (S.C.); lucien.robinault@gmail.com (L.R.); jimmy.lauber@uphf.fr (J.L.); \\ juancarlos.Arceo@uphf.fr (J.C.A.) \\ 3 Mech-Sense, Department of Gastroenterology and Hepatology, Aalborg University Hospital, Aalborg 9000, \\ Denmark; m.navid@rn.dk (M.S.N.); rasmus.nedergaard@nzchiro.co.nz (R.W.N.) \\ 4 New Zealand College of Chiropractic, Auckland 1060, New Zealand; heidi.haavik@nzchiro.co.nz \\ 5 Health and Rehabilitation Research Institute, Auckland University of Technology, Auckland 0627, \\ New Zealand; urashid@aut.ac.nz \\ * Correspondence: imran.niazi@nzchiro.co.nz; Tel.: +64-9526-6789
}

Received: 9 October 2018; Accepted: 1 November 2018; Published: 3 November 2018

check for updates

\begin{abstract}
Brain-computer interfaces (BCIs) can be used to induce neural plasticity in the human nervous system by pairing motor cortical activity with relevant afferent feedback, which can be used in neurorehabilitation. The aim of this study was to identify the optimal type or combination of afferent feedback modalities to increase cortical excitability in a BCI training intervention. In three experimental sessions, 12 healthy participants imagined a dorsiflexion that was decoded by a BCI which activated relevant afferent feedback: (1) electrical nerve stimulation (ES) (peroneal nerve-innervating tibialis anterior), (2) passive movement (PM) of the ankle joint, or (3) combined electrical stimulation and passive movement (Comb). The cortical excitability was assessed with transcranial magnetic stimulation determining motor evoked potentials (MEPs) in tibialis anterior before, immediately after and $30 \mathrm{~min}$ after the $\mathrm{BCI}$ training. Linear mixed regression models were used to assess the changes in MEPs. The three interventions led to a significant $(p<0.05)$ increase in MEP amplitudes immediately and $30 \mathrm{~min}$ after the training. The effect sizes of Comb paradigm were larger than ES and PM, although, these differences were not statistically significant $(p>0.05)$. These results indicate that the timing of movement imagery and afferent feedback is the main determinant of induced cortical plasticity whereas the specific type of feedback has a moderate impact. These findings can be important for the translation of such a BCI protocol to the clinical practice where by combining the $\mathrm{BCI}$ with the already available equipment cortical plasticity can be effectively induced. The findings in the current study need to be validated in stroke populations.
\end{abstract}

Keywords: brain-computer interface; neural plasticity; peripheral nerve stimulation; exoskeleton; neurorehabilitation; transcranial magnetic stimulation (TMS)

\section{Introduction}

Several studies have suggested that brain-computer interfaces (BCIs) can be used for motor rehabilitation after stroke [1-6]. Patients are asked to imagine or attempt to perform a movement 
which is then detected through EEG recordings and translated into a device command that provide feedback to the patient; this can, e.g., be somatosensory afferent or visual feedback. Especially the somatosensory afferent feedback may be important for rehabilitation since it is a motor learning task $[7,8]$. The underlying physiological mechanism for motor learning is neural plasticity [9], and it has been shown in several studies that the neural plasticity can be induced by BCI training [10-12]. In these studies, it has been suggested that Hebbian-associative plasticity is induced by pairing motor cortical activity with relevant somatosensory afferent feedback in the same way as has been done in paired associative stimulation protocols [13]. The difference between BCI and paired associative stimulation is that the motor cortex is activated through imagined movements rather than by stimulation so that brain activation corresponds to the natural activity [14]. The imagined movement must be detected on a single-trial level immediately during the execution to obtain the strict temporal association between motor cortical activity and somatosensory afferent feedback which is needed to induce plasticity [10], as validated in several previous studies [15-19]. It has previously been shown that proprioceptive/somatosensory afferent feedback induces more cortical changes than visual feedback when combined with a BCI [20]. It has been suggested that improved BCI performance could increase the induction of plasticity [11]. Thus, different approaches have been investigated to optimize the BCI performance, such as using different signal processing techniques [21-28], combining two different control signals [29], training the user [30], and facilitate motor imagination [31]. In addition to the technical optimization of the BCI, it is likely that the induction of plasticity can be improved by identifying the optimal type of afferent feedback. Motor-driven orthotic devices and exoskeletons have been used in BCI-related studies and electrical stimulation has been applied with different parameters in terms of stimulation frequency, intensity and location (nerve or muscle stimulation) [3,10,12,32-38]. These afferent feedback modalities have all been shown to induce plasticity when they were paired with motor cortical activity from imagined or executed movements. Different electrical stimulation frequencies, parameters and locations as well as passive movements have been compared, but due to a large number of combinations it is not feasible to include every combination in a single study. The aim of the current study is to investigate the induction of plasticity when imagined movements are detected in a self-paced BCI system and paired with: (1) single-pulse electrical nerve stimulation, (2) passive movement through a motorized orthotic device, and (3) the combination of electrical nerve stimulation and passive movement. The plasticity induction of the BCI training is evaluated through motor evoked potentials (MEPs) elicited with transcranial magnetic stimulation (TMS). We hypothesize that it is possible to induce plasticity in all three scenarios, but that there is an additive effect by combining electrical stimulation with passive movements.

\section{Materials and Methods}

\subsection{Participants}

Twelve healthy participants were included in the study (four women: $25 \pm 4$ years). All participants gave their written informed consent prior to the experiment, and they filled in a TMS questionnaire for eligibility based on the recommendations in [39]. All procedures were approved by the Northern B Health and Disability ethical committee (17/NTB/261) New Zealand. All the procedures were carried out according to the Helsinki Declaration.

\subsection{Experimental Setup}

The experiment was divided into three experimental sessions that all followed the same structure where the only difference was the type of afferent feedback: (1) BCI-triggered electrical nerve stimulation, (2) BCI-triggered passive movements, and (3) BCI-triggered electrical nerve stimulation and passive movement. The order of the experimental sessions was randomized, and experimental sessions were separated by at least $24 \mathrm{~h}$. Initially, the participant was seated in a comfortable chair and asked to do 50 self-paced movements, while continuous EEG and EMG was recorded. 
These movements were used to calibrate the BCI system. After the calibration of the BCI system, the stimulation sites and parameters for the TMS and electrical stimulation were determined. Before the $\mathrm{BCI}$ intervention, 15 MEPs were recorded; this was repeated immediately after and 30 min after the BCI intervention. The BCI system was calibrated in each of the three experimental sessions. The BCI intervention lasted until 50 correct parings of imagined movements and afferent feedback were obtained.

\subsection{Recordings}

\subsubsection{EEG}

Ten channels of continuous EEG were recorded from FP1, F3, Fz, F4, C3, Cz, C4, P3, Pz, and P4 with a sampling frequency of $2048 \mathrm{~Hz}$ (Refa amplifiers, TMSi, TMS International, Zuidplas, The Netherlands). FP1 was used to monitor eye movements and eye blinks. The channels were referenced to the right earlobe. During the experiment all channels were below $5 \mathrm{k} \Omega$. The participants were instructed to sit as still as possible and to minimize blinking.

\subsubsection{Surface EMG}

MEPs were recorded with surface EMG electrodes. Two electrodes (20 mm Blue Sensor Ag- $\mathrm{AgCl}$, AMBU A/S, Ballerup, Denmark) were placed on the belly of the right tibialis anterior muscle in a bipolar configuration with the ground electrode placed on the tibia. The signals were amplified with a custom-made amplifier with a gain of 1000 and a sampling frequency of $4000 \mathrm{~Hz}$. The signals were band-pass filtered from $20-1000 \mathrm{~Hz}$.

\subsection{Stimulation and Motorized Orthotic Device}

\subsubsection{Transcranial Magnetic Stimulation}

Single pulse TMS was used to elicit MEPs in the tibialis anterior with a Magstim 200 (Magstim Company, Dyfed, UK) using a figure-of-eight double-cone coil with a posterior-anterior current direction. Before recordings, the optimal stimulation site was determined as the site where the largest peak-to-peak amplitude of the MEP in tibialis anterior was elicited compared to the adjacent areas. This area was marked to make sure the coil was placed in the same position for the pre-, post-, and post-30 min intervention measurements. The resting threshold was then determined as the lowest stimulator output where five out of 10 peak-to-peak amplitude MEPs were greater than $50 \mu \mathrm{V}$. In the pre-, post-, and post-30 min intervention measurements, 15 stimuli were given at $120 \%$ of the resting threshold. Each stimulus was separated by $5-7$ s.

\subsubsection{Electrical Stimulation}

Peripheral nerve stimulation was delivered to the deep branch of the common peroneal nerve supplying the tibialis anterior. The electrical stimulation was delivered through two stimulation electrodes (32 mm, PALS, Platinum, Patented Conductive Neurostimulation Electrodes, Axelgaard Manufacturing Co., Ltd., Fallbrook, CA, USA) that were placed on the skin overlying the nerve with the cathode placed proximal and the anode placed distal. The optimal stimulation site was determined by searching for the location that determined activity in the tibialis anterior without any activity in synergistic or antagonistic muscles (as determined by palpation of the muscles). The motor threshold was then determined as the lowest intensity required to elicit a palpable response in the tibialis anterior tendon. In the two interventions involving electrical stimulation, a single 1-ms wide pulse was delivered with an intensity corresponding to $110 \%$ of the motor threshold. 


\subsubsection{Passive Movements Through the Motorized Orthotic Device}

The passive dorsiflexion ankle movement was delivered through a custom-made motorized orthotic device based on the design of an ergometer [40] coupled with a CAHB-21 linear actuator (SKF, Goteborg, Sweden) arranged together to rotate the ankle joint [41,42]. The foot and leg were fixed to the orthosis with straps. The initial position of the orthotic device corresponded to $110^{\circ}$ of plantar flexion. The orthosis performed a $15^{\circ}$ dorsiflexion rotation around the ankle joint at a constant angular speed of $40^{\circ} \cdot \mathrm{s}^{-1}$.

\subsection{Brain-Computer Interface}

The BCI system used in this study has been previously described [11]. Briefly, the system was trained from 50 self-paced movements. From these movements, an EEG signal template of the initial negative phase of the movement-related cortical potentials was extracted from the onset of the movement (determined from the EMG). For this purpose, the EEG was band-pass filtered from 0.05-10 Hz with a 2nd-order zero-phase shift Butterworth filtered, down sampled (at $32 \mathrm{~Hz}$ ) and filtered with an optimised spatial filter [15] with $\mathrm{Cz}$ as the centre electrode. Template matching was used to calibrate the BCI detector as explained in $[11,15]$. The threshold for detecting the movements was obtained through a receiver operating characteristics curve to achieve a trade-off between the true positive and false positive detections/10 min (length of the training data set) as shown in Figure 1. When the output from the template matching exceeded the threshold, the BCI system registered it as a movement. During the $\mathrm{BCI}$ intervention, the $\mathrm{BCI}$ system was disabled for five seconds after an event was detected and in this interval the participant indicated if it was a true positive detection or a false positive detection. The participants also indicated the presence of false negatives. Moreover, the detector was disabled if the activity in FP1 exceeded a $125 \mu \mathrm{V}$ threshold. The BCI system performance was evaluated through the true positive rate (TPR) and number of false positive detections per minute (FPm).

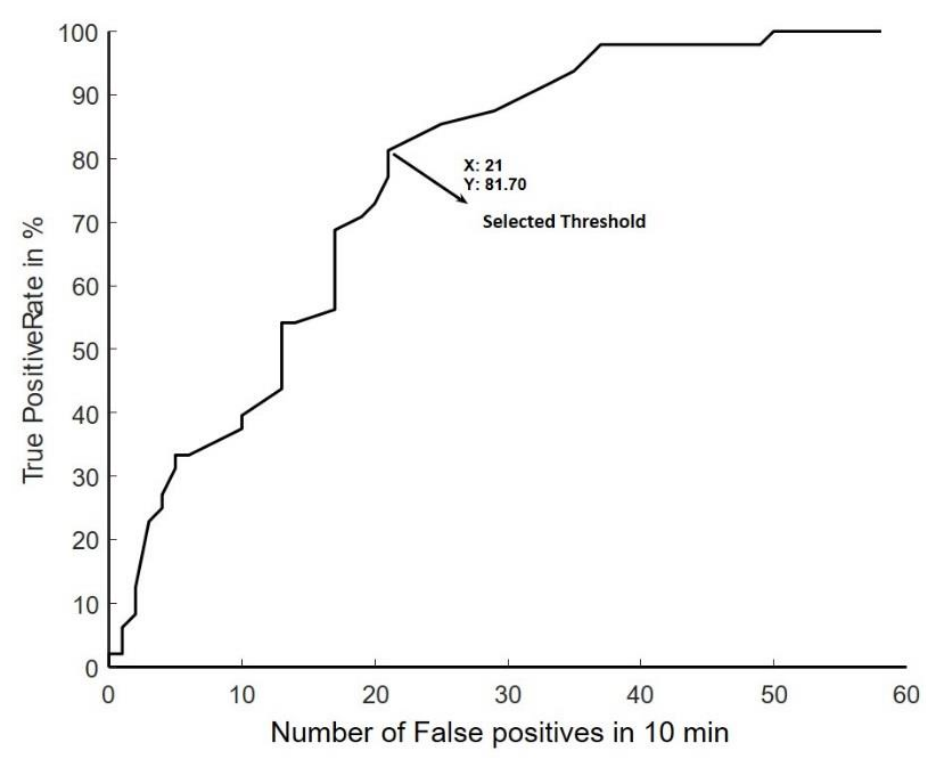

Figure 1. ROC curve, from one training set which was $10 \mathrm{~min}$ long to show the trade-off between TPR and $\mathrm{FP}^{\prime} \mathrm{s}$.

\subsection{Statistical Analysis}

In the statistical analysis, we were concerned with three questions: (a) Did the BCI performance have an effect on the MEP amplitude? (b) did the pre- to post- and post-30 treatment effect of electrical stimulation (ES), passive movements (PM), and electrical stimulation combined with passive movements (Comb) induced plasticity? (c) What was the difference in these effects across the three 
paradigms? We evaluated (a) in terms of absolute units $(\mathrm{mV})$ using blinded covariate analysis [43], and (b), (c) in terms of both absolute units and relative units (\% change). For absolute units, we computed the peak-peak amplitudes of the MEPs and averaged them across the 15 trials. For the relative units, we computed subject wise \% changes from the averaged peak-peak amplitudes of the MEPs as (post- - pre-)/pre- $\times 100$.

To answer these questions, we setup linear mixed regression models. In all the models, time, session, and subject were codified as categorical variables. All the remaining variables were codified as continuous. The statistical analysis was performed in R ( $\mathrm{R}$ Foundation for Statistical Computing) version 3.5.0. lme4 package version 1.1-17 was used for fitting all the models [44].

For question (a), four performance metrices were considered as covariates: (i) true positive rate (TPR), (ii) false positives per minutes $\left(\mathrm{FP}_{\mathrm{m}}\right)$, (iii) time taken to complete the task $\left(\mathrm{T}_{\mathrm{t}}\right.$ ), and (iv) total number of movement repetitions executed $\left(\mathrm{M}_{\mathrm{r}}\right)$. Following linear mixed model, presented in $\mathrm{R}$ formula syntax, was used for this purpose:

$$
\mathrm{MEP}_{\mathrm{abs}} \sim 1+\mathrm{MEP}_{\mathrm{pre}}+\mathrm{Time}+\mathrm{TPR}+\mathrm{FP}_{\mathrm{m}}+\mathrm{T}_{\mathrm{t}}+\mathrm{M}_{\mathrm{r}}+(1 \mid \text { Subject })
$$

This model estimates MEP amplitudes at two time points (post- and post-30) while also considering the effect of pre- MEP amplitudes ( $\left.\mathrm{MEP}_{\text {pre }}\right), \mathrm{TPR}, \mathrm{FP}_{\mathrm{m}}, \mathrm{Tt}$, and $\mathrm{Mr}$. The random intercept term for subjects ( 1 ISubject) entered into the model, estimates the variance across the subjects. This model was fitted to data from the three sessions. However, the Session variable was not added to the model to keep the analysis blinded as suggested by Kunz et. al. [43]. This procedure has two benefits. First, it allows for an unbiased selection of covariates as the selection is done before obtaining the final results. Second, it leaves out unnecessary covariates which can potentially act as noise in the final model, thus, improving the statistical power. It was planned a priori that a covariate which explained greater than or equal to $5 \%$ of the variance in the data will be considered as potentially having a significant effect on the MEP amplitudes. Furthermore, it will be added to models used for answering questions (b) and (c) in order to statistically control for its effect. Semi-partial $\mathrm{R}^{2}$ statistic was obtained using the Kenward-Roger method as a measure of explained variance. The r2glmm package version 0.1.2 was used for this purpose [45].

For questions (b) and (c), following model, expressed as an R formula, was used for absolute units:

$$
\mathrm{MEP}_{\mathrm{abs}} \sim 1+\text { Session } \times \text { Time }+\mathrm{MEP}_{\text {pre }}+\mathrm{T}_{\mathrm{t}}+(1 \mid \text { Subject }: \text { Session })
$$

This model estimates MEP amplitude across the three sessions (ES, PM, Comb) at both time points (post-, post-30) while adjusting for the pre- MEP amplitudes. This model also controls for total time taken to complete the task as it explained more than $5 \%$ of the variance in MEP amplitudes. This model is similar to model 1 suggested by Twisk et al. [46] with two important improvement. First, as the subjects across the sessions were same and it is reasonable to assume that the subjects respond differently to the three paradigms, thus, we used a subject and session wise random intercept (1|Subject : Session) to estimate the between subject variance. This model also suits to the repeated measures design of this study. Second, as the MEP amplitudes are always positive and are not normally distributed, we used Gamma distribution to model the data. The choice of the link function (identity or log) was evaluated using Akaike information criterion corrected for small samples (AICc). The AICc penalises both under fitting and over fitting. We used the log link.

For relative units, we setup the same model with the exception that we used Gaussian distribution and identity link. The residuals of the model were normally distributed. The model, expressed as an $\mathrm{R}$ formula, is given below:

$$
\mathrm{MEP}_{\%} \sim 1+\text { Session } \times \text { Time }+\mathrm{MEP}_{\text {pre }}+\mathrm{T}_{\mathrm{t}}+(1 \mid \text { Subject }: \text { Session })
$$


Significance level was set at 0.05 . Effects estimated by the model were reported with their standard errors. Pair-wise contrasts were performed with Tukey's HSD method.

\section{Results}

\subsection{BCI Performance}

The performance metrices and the corresponding variance explained statistics are given in Table 1. Time taken to complete the task explained $6 \%$ of the variance in MEP amplitudes and, therefore, was included as a covariate to statistically control its effect in the subsequent models used to estimate $\mathrm{MEP}_{\mathrm{abs}}$ and $\mathrm{MEP}_{\%}$.

Table 1. BCI performance metrices and percentage of variance explained in MEP amplitudes by each metric.

\begin{tabular}{ccc}
\hline Performance Metric & Mean [min, max] & Variance Explained Partial $\mathbf{R}^{\mathbf{2}} \mathbf{( \% )}$ \\
\hline $\mathrm{TPR}$ & $78.13[58.82,96.15] \%$ & 1.5 \\
$\mathrm{FP}_{\mathrm{m}}$ & $1.21[0.22,4.62]$ & 0.8 \\
$\mathrm{~T}_{\mathrm{t}}$ & $13.42[7,23] \mathrm{min}$ & 6.0 \\
$\mathrm{M}_{\mathrm{r}}$ & $64.36[52,85]$ & 0.3 \\
\hline
\end{tabular}

The linear trends between $\mathrm{T}_{\mathrm{t}}$ and $\mathrm{MEP}_{\mathrm{abs}}$ and $\mathrm{MEP} \%$ estimated by the statistical models are given in Table 2. These results suggest that the time taken to complete the task did not have a statistically significant effect on the MEP amplitudes.

Table 2. The linear trends between $\mathrm{T}_{\mathrm{t}}$ and $\mathrm{MEP}_{\mathrm{abs}}$ and $\mathrm{MEP} \%$ estimated by the statistical models.

\begin{tabular}{cccc}
\hline Trend for $\mathbf{T}_{\mathbf{t}}$ & Estimate & Std. Error & $\boldsymbol{p}, \mathbf{H}_{\mathbf{0}}: \boldsymbol{\mu}=\mathbf{0}$ \\
\hline With $\mathrm{MEP}_{\mathrm{abs}}(\mathrm{mV} / \mathrm{min})$ & 0.01 & 0.02 & $z=0.65, p=0.51$ \\
With $\mathrm{MEP}_{\%}(\% / \mathrm{min})$ & 1.32 & 2.79 & $\mathrm{t}[31]=0.47, p=0.63$ \\
\hline
\end{tabular}

As the remaining performance metrices did not explain considerable $\left(R^{2}\right.$ partial $\left.<5 \%\right)$ variance in the data, they were not added to the statistical models and, thus, their trends were not estimated. To further elaborate on the differences in TPR and $\mathrm{FP}_{\mathrm{m}}$ across sessions, their means and standard errors are given in Figure 2. One-way ANOVAs suggested that there was no difference between the sessions in terms of both the true positive rate $(\mathrm{F}(2,22)=0.001 ; p=1.0)$ or number of false positive detections per minute $(\mathrm{F}(2,22)=0.59 ; p=0.57)$. These results together with the explained variance statistic suggest that none of the BCI performance metrices had any significant effect on the MEP amplitudes. 

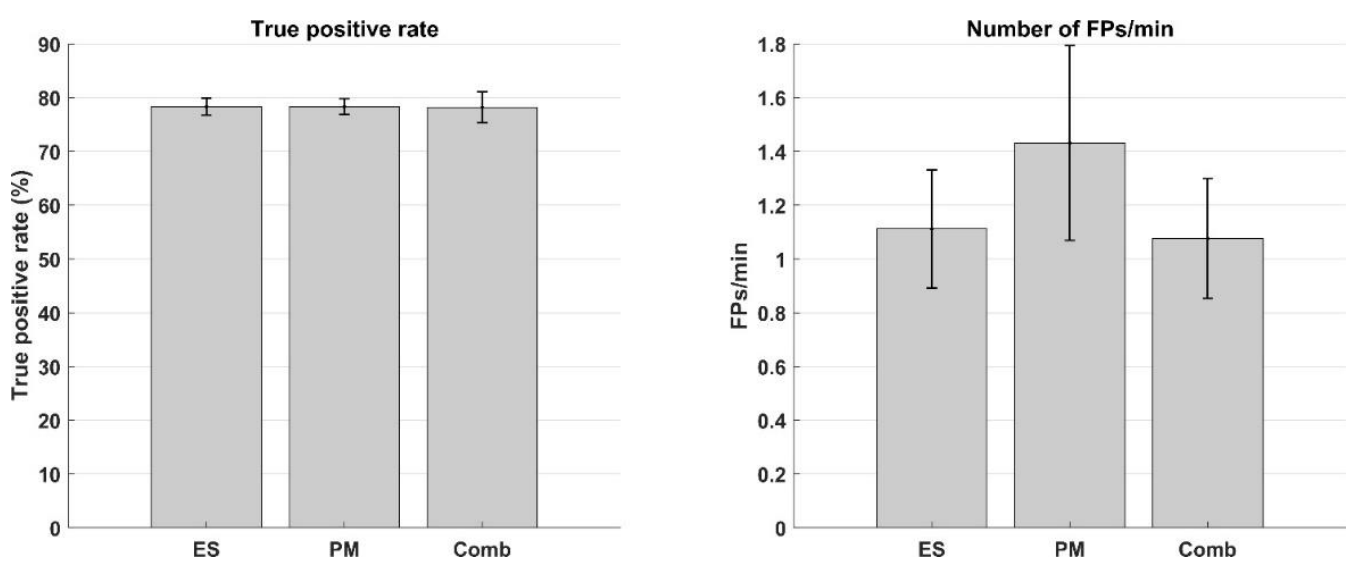

Figure 2. (Left) True positive rate (mean \pm standard error) across all subjects. (Right) Number of false positive detections per minute (mean \pm standard error) across all subjects. 'ES': Electrical stimulation, 'PM': Passive movement, and 'Comb': Combined electrical stimulation and passive movement.

\subsection{MEP Size}

The peak-peak MEP amplitudes for the subjects are plotted in Figure 3. The individual trends suggest that there was a larger increase in pre- to post-MEP amplitude in case of ES and Comb compared to PM.

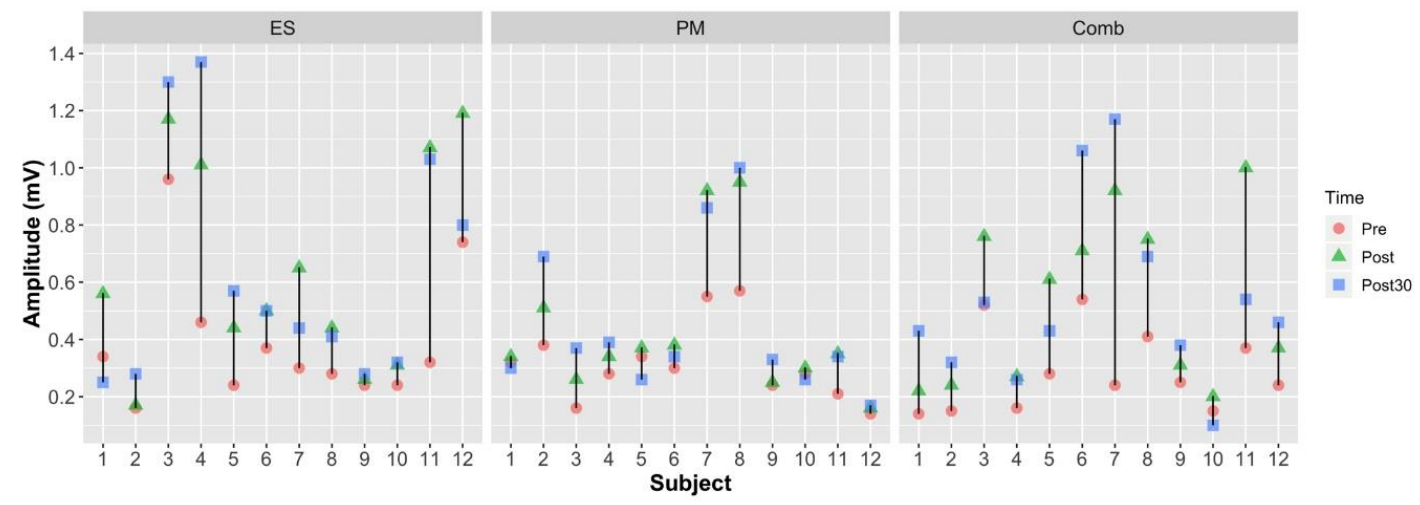

Figure 3. Peak-peak MEP amplitudes for all the subjects for pre- to post- and post-30 raw values.

The pre- to post-effect sizes estimated from the statistical models are given in Table 3 . These effects were computed with $T_{t}$ set to its mean value (13.42 min). Similarly, pair-wise contrasts across the sessions at the two time points are given in Table 3. The pair-wise contrasts across sessions and time are given in Tables 4 and 5, respectively. As a log link was used in modelling the MEP amplitudes in absolute units, thus the contrasts performed on the log scale are presented as ratios on the response scale.

These results suggest that the three paradigms increased $(p<0.05)$ the MEP amplitudes from preto post- and post-30 in terms of the absolute units. The effect sizes of Comb paradigm were larger than ES and PM, although, these differences were not statistically significant $(p>0.05)$. 
Table 3. Pre- to post- and post 30-effect sizes along with the standard errors estimated from the statistical models.

\begin{tabular}{|c|c|c|c|c|}
\hline Session & Time & $\mathrm{MEP}_{\mathrm{abs}}(\mathrm{mV})$ & Std. Error (mV) & $z, p, \mathrm{H}_{0}: \mu=0$ \\
\hline ES & & 0.21 & 0.05 & $z=-6.97, p<0.001$ \\
\hline PM & post- & 0.17 & 0.03 & $z=-8.83, p<0.001$ \\
\hline Comb. & & 0.22 & 0.04 & $z=-7.98, p<0.001$ \\
\hline ES & & 0.20 & 0.05 & $z=-7.13, p<0.001$ \\
\hline PM & post-30 & 0.19 & 0.04 & $z=-8.40, p<0.001$ \\
\hline Comb. & & 0.22 & 0.04 & $z=-8.00, p<0.001$ \\
\hline Session & Time & $\mathrm{MEP}_{\%}(\%)$ & Std. Error (\%) & $\mathrm{t}[\mathrm{df}], p, \mathrm{H}_{0}: \mu=0$ \\
\hline ES & & 81.26 & 32.86 & $\mathrm{t}[35.29]=2.47, p=0.02$ \\
\hline PM & post- & 41.16 & 29.59 & $\mathrm{t}[36.37]=1.39, p=0.17$ \\
\hline Comb. & & 94.90 & 27.99 & $\mathrm{t}[37.05]=3.39, p<0.01$ \\
\hline ES & & 80.44 & 32.86 & $\mathrm{t}[35.29]=2.45, p=0.02$ \\
\hline PM & post-30 & 56.37 & 29.59 & $\mathrm{t}[36.37]=1.91, p=0.06$ \\
\hline Comb. & & 104.69 & 27.99 & $\mathrm{t}[37.05]=3.74, p<0.001$ \\
\hline
\end{tabular}

Table 4. Contrasts across sessions and their standard errors estimated from the statistical models.

\begin{tabular}{ccccc}
\hline Contrast & Time & Ratio & Std. Error (Ratio) & $z, p, \mathbf{H}_{\mathbf{0}}: \boldsymbol{\mu}=\mathbf{1}$ \\
\hline ES/PM & & 1.23 & 0.25 & $z=0.99, p=0.57$ \\
ES/Comb. & post- & 0.94 & 0.19 & $z=-0.32, p=0.95$ \\
PM/Comb. & & 0.77 & 0.15 & $z=-1.32, p=0.39$ \\
\hline ES/PM & & 1.08 & 0.22 & $z=0.39, p=0.92$ \\
ES/Comb. & post-30 & 0.91 & 0.18 & $z=-0.46, p=0.89$ \\
PM/Comb. & & 0.84 & 0.17 & $z=-0.85, p=0.67$ \\
\hline Contrast & Time & Difference (\%) & Std. Error $\mathbf{( \% )}$ & $\mathrm{t}[\mathbf{d f}], \boldsymbol{p}, \mathbf{H}_{\mathbf{0}}: \boldsymbol{\mu}=\mathbf{0}$ \\
\hline ES - PM & & 40.10 & 29.90 & $\mathrm{t}[42.22]=1.34, p=0.38$ \\
ES - Comb. & post- & -13.64 & 301.16 & $\mathrm{t}[42.00]=-0.45, p=0.89$ \\
PM - Comb. & & -53.74 & 29.77 & $\mathrm{t}[42.33]=-1.81, p=0.18$ \\
\hline ES - PM & & 24.06 & 29.90 & $\mathrm{t}[42.22]=0.81 p=0.70$ \\
ES - Comb. & post-30 & -24.25 & 30.16 & $\mathrm{t}[42.00]=-0.80, p=0.70$ \\
PM - Comb. & & -48.31 & 29.77 & $\mathrm{t}[42.33]=-1.62, p=0.25$ \\
\hline
\end{tabular}

Table 5. Contrasts across time and their standard errors estimated from the statistical models.

\begin{tabular}{ccccc}
\hline Contrast & Session & Ratio & Std. Error (Ratio) & $\boldsymbol{z}, \boldsymbol{p}, \mathbf{H}_{\mathbf{0}}: \boldsymbol{\mu}=\mathbf{1}$ \\
\hline \multirow{2}{*}{ post-/post-30 } & ES & 1.03 & 0.08 & $z=0.42, p=0.67$ \\
& PM & 0.94 & 0.07 & $z=-1.13, p=0.26$ \\
& ES+PM & 1.00 & 0.08 & $z=0.05, p=0.96$ \\
\hline Contrast & Session & Difference (\%) & Std. Error (\%) & $\mathbf{t}[\mathbf{d f}], \boldsymbol{p}, \mathbf{H}_{\mathbf{0}}: \boldsymbol{\mu}=\mathbf{0}$ \\
\hline \multirow{2}{*}{ post- -} & ES & 0.82 & 16.74 & $\mathrm{t}[33]=0.05, p=0.96$ \\
post-30 & PM & -15.22 & 16.74 & $\mathrm{t}[33]=-0.91, p=0.37$ \\
& ES+PM & -9.79 & 16.74 & $\mathrm{t}[33]=-0.59, p=0.56$ \\
\hline
\end{tabular}

\section{Discussion}

The study confirmed that neural plasticity can be induced by BCI-triggered electrical stimulation or passive movements. However, the three afferent feedback modalities did not differ in their effects on plasticity. The contrasts suggested that electrical stimulation consistently resulted in slightly higher mean MEP amplitudes than passive movement and the combination of passive movement with electrical stimulation consistently resulted in slightly higher mean MEP amplitudes than electrical stimulation alone. 


\subsection{Effect of BCI-Triggered Afferent Feedback}

All three types of afferent feedback induced neural plasticity when combined with the BCI, but there was no statistically significant difference between the types of afferent feedback although larger percentage changes from pre-to post- and pre-to post-30 were obtained when electrical stimulation was involved. However, there was a large variability between participants, presumably due to factors such as attention and time of the day [47]. It is also likely that there might be a difference in the amount and type of sensory feedback that is sent to the brain, which depends on the activation of afferents and the type of receptors that are active during the electrical stimulation (no movement of the foot) and the passive movement. For the electrical stimulation, only the nerve innervating the tibialis anterior was stimulated, thus only low-threshold afferents were recruited [48]. Conversely, during the passive movements, cutaneous and high threshold afferents would be activated because of joint movement. Moreover, other non-muscle afferents should also be active via a transcortical loop resulting in an activation which was close to a voluntary dorsiflexion [48,49]. However, different types of sensory feedback may have different effects on the cortical motor networks when applied as part of an intervention [50]. The latency of the different types of afferent feedback to reach cortex was presumably similar [51,52]. Moreover, another advantage of having the electrical stimulation over peripheral nerve trunk is that it generates contraction facilitated via central pathways by maximizing the afferent (sensory) volley to spinal cord where sensorimotor integration occurs, resulting in optimal recruitment of the spinal motor neuron [28]. It is known in the literature that, If the central contribution is maximized it can lead to reduced muscle atrophy which in turn can be used to restore movement in persons with movement disorders [53].

The observation of no difference between electrical stimulation and passive movements supports previous findings by Mrachacz-Kersting et al. [34]. This means that the choice of the type of afferent feedback modality may not be crucial, and it should rather be selected based on the available equipment in the rehabilitation centers or by the comfort of the patient. However, contrary to the previous study by Mrachacz-Kersting et al. [34], in the current study the BCI operated in a self-paced way.

The pros of the electrical stimulation are that it is low-cost, and it has been used by many, but the cons are that electrical stimulation can lead to muscle fatigue (especially when using functional electrical stimulation) and it may be painful for some patients (depending on the stimulation parameters). The pros of the motor-driven orthotic device are that there is no muscle fatigue and the movement can be executed with great precision, so it mimics a natural movement. The cons of the motor-driven orthotic device are that it is more expensive that the electrical stimulation and it is less portable. To overcome this latter disadvantage, we developed and used a transportable motorized ergometer [34,35]. It remains to optimize the passive-movement feedback so that it is as close as possible to the dynamic of a real movement.

\subsection{Neural Mechanisms}

It has been suggested in several BCI studies [4,10-12] that the neural mechanisms for the changes observed in BCI intervention studies are similar to that of paired associated stimulation [13], which rely on long-term potentiation properties such as rapid onset, persistence on cessation of stimulation and associativity but with likely differences in the origins of those effects [54]. The increase in cortical excitability was retained at least for $30 \mathrm{~min}$ following the intervention [55]. It has previously been shown that this this type of BCI intervention is specific $[4,10]$, which is another indication of that it is long-term potentiation-like plasticity that is induced. Furthermore, the origin of the neural plastic changes were not assessed, but it has been suggested that it is likely to be changes in the cortical plasticity $[10-12,34]$. 


\subsection{Limitations}

In the current study, we did not detect a statistically significant difference for the alternative hypothesis that ES and PM combined (Comb) have a larger effect in terms of inducing cortical excitability. As the estimated effect sizes supported this hypothesis, the potential reason for not achieving statistical significance seems to be the small sample size $(n=12)$. Sample size for this study was based on the previous studies [10-12,34,55] in which it ranged between 8 and 12. Future studies can plan a better sample size by using the estimated effects and their standard errors reported in the current study. Another limitation is the effect of the BCI intervention without sensory feedback was not tested as well as afferent feedback without the BCI intervention. However, it has previously been shown that 50 electrical stimuli or passive movements alone do not change the size of the MEPs $[10,12]$. The same has been found for the BCI intervention without any afferent feedback [10,12]. All findings in the current study are based on healthy volunteers which limit the generalization/transfer of the results to stroke rehabilitation. However, similar work has been done for the upper limb where stroke patients have received upper limb BCI training using functional electrical stimulation [56] and rehabilitation robots where functional improvements have been shown [3,5,57]. It is likely that similar beneficial effects may be observed for the lower limbs as well [4].

\section{Conclusions}

It was shown that neural plasticity could be induced with electrical stimulation, passive movement and the combination of electrical stimulation and passive movement when combined with a BCI.

In conclusion, current study indicates that timing of movement imagery and afferent feedback is the main determinant of inducing cortical plasticity whereas the specific type of feedback has moderate impact. These different types of feedback can be used based on the most practical and convenient one for the patient and caregivers should be selected. This, or a similar, investigation need to be performed with stroke patients in future studies to investigate if the results from healthy subjects can be translated to stroke patients. In such studies, other important aspects can also be included, such as an extended training period, and the measurement of clinically relevant outcomes and their correlation with induction of cortical excitability. Moreover, the usability of such a BCI combined with either electrical stimulation or passive movement need to be investigated. These investigations can provide insights into the transfer of $\mathrm{BCI}$ enabled interventions to clinical practice or potential use at home.

Author Contributions: Conceptualization: M.J., S.C., H.H., and I.K.N.; methodology: M.J., S.C., H.H., and I.K.N.; software: M.S.N., R.W.N., and I.K.N.; resource (mechanical and control part of the orthotic device): L.R., J.C.A., J.L., and S.C.; validation: U.R., L.R., and J.C.A.; data collection: M.S.N., R.W.N., S.C., U.R., and I.K.N.; formal analysis: M.J., U.R.; resources: H.H., L.L.; data curation: U.R., L.R., J.C.A., M.S.N., and R.W.N.; writing-original draft preparation: M.J.; writing_review and editing: all authors; visualization: U.R.; supervision: H.H.;. J.L.; project administration: I.K.N. and S.C.; FUNDING acquisition: H.H. and J.L.

Funding: This research received no external funding but H.H. and J.L. received internal institutional grants to cover the expenses of the consumable and project cost.

Conflicts of Interest: The authors declare no conflict of interest.

\section{References}

1. Ang, K.K.; Guan, C. Brain-Computer Interface in Stroke Rehabilitation. J. Comput. Sci. Eng. 2013, 7, $139-146$. [CrossRef]

2. Ang, K.K.; Guan, C.; Phua, K.S.; Wang, C.; Zhou, L.; Tang, K.Y.; Ephraim Joseph, G.J.; Kuah, C.W.K.; Chua, K.S.G. Brain-computer interface-based robotic end effector system for wrist and hand rehabilitation: Results of a three-armed randomized controlled trial for chronic stroke. Front. Neuroeng. 2014, 7, 30. [CrossRef] [PubMed]

3. Ang, K.K.; Chua, K.S.G.; Phua, K.S.; Wang, C.; Chin, Z.Y.; Kuah, C.W.K.; Low, W.; Guan, C. A Randomized Controlled Trial of EEG-Based Motor Imagery Brain-Computer Interface Robotic Rehabilitation for Stroke. Clin. EEG Neurosci. 2015, 46, 310-320. [CrossRef] [PubMed] 
4. Mrachacz-Kersting, N.; Jiang, N.; Stevenson, A.J.T.; Niazi, I.K.; Kostic, V.; Pavlovic, A.; Radovanovic, S.; Djuric-Jovicic, M.; Agosta, F.; Dremstrup, K.; Farina, D. Efficient neuroplasticity induction in chronic stroke patients by an associative brain-computer interface. J. Neurophysiol. 2016, 115, 1410-1421. [CrossRef] [PubMed]

5. Frolov, A.A.; Mokienko, O.; Lyukmanov, R.; Biryukova, E.; Kotov, S.; Turbina, L.; Nadareyshvily, G.; Bushkova, Y. Post-stroke Rehabilitation Training with a Motor-Imagery-Based Brain-Computer Interface (BCI)-Controlled Hand Exoskeleton: A Randomized Controlled Multicenter Trial. Front. Neurosci. 2017, 11, 400. [CrossRef] [PubMed]

6. Pichiorri, F.; Morone, G.; Pisotta, I.; Petti, M.; Molinari, M.; Astolfi, L.; Cincotti, F.; Mattia, D. BCI for Stroke Rehabilitation: A Randomized Controlled Trial of Efficacy. In Proceedings of the Fifth International Brain-Computer Interface Meeting, Pacific Grove, CA, USA, 3-7 June 2013.

7. Pavlides, C.; Miyashita, E.; Asanuma, H. Projection from the sensory to the motor cortex is important in learning motor skills in the monkey. J. Neurophysiol. 1993, 70, 733-741. [CrossRef] [PubMed]

8. Krakauer, J.W. Motor learning: Its relevance to stroke recovery and neurorehabilitation. Curr. Opin. Neurol. 2006, 19, 84-90. [CrossRef] [PubMed]

9. Pascual-Leone, A.; Nguyet, D.; Cohen, L.G.; Brasil-Neto, J.P.; Cammarota, A.; Hallett, M. Modulation of muscle responses evoked by transcranial magnetic stimulation during the acquisition of new fine motor skills. J. Neurophysiol. 1995, 74, 1037-1045. [CrossRef] [PubMed]

10. Mrachacz-Kersting, N.; Kristensen, S.R.; Niazi, I.K.; Farina, D. Precise temporal association between cortical potentials evoked by motor imagination and afference induces cortical plasticity. J. Physiol. 2012, 590, 1669-1682. [CrossRef] [PubMed]

11. Niazi, I.K.; Mrachacz-Kersting, N.; Jiang, N.; Dremstrup, K.; Farina, D. Peripheral Electrical Stimulation Triggered by Self-Paced Detection of Motor Intention Enhances Motor Evoked Potentials. IEEE Trans. Neural Syst. Rehabil. Eng. 2012, 20, 595-604. [CrossRef] [PubMed]

12. Xu, R.; Jiang, N.; Mrachacz-Kersting, N.; Lin, C.; Asin Prieto, G.; Moreno, J.C.; Pons, J.L.; Dremstrup, K.; Farina, D. A Closed-Loop Brain-Computer Interface Triggering an Active Ankle-Foot Orthosis for Inducing Cortical Neural Plasticity. IEEE Trans. Biomed. Eng. 2014, 61, 2092-2101. [CrossRef] [PubMed]

13. Stefan, K.; Kunesch, E.; Cohen, L.G.; Benecke, R.; Classen, J. Induction of plasticity in the human motor cortex by paired associative stimulation. Brain 2000, 123, 572-584. [CrossRef] [PubMed]

14. De Vries, S.; Mulder, T. Motor imagery and stroke rehabilitation: A critical discussion. J. Rehabil. Med. 2007, 39, 5-13. [CrossRef] [PubMed]

15. Niazi, I.K.; Jiang, N.; Tiberghien, O.; Nielsen, J.F.; Dremstrup, K.; Farina, D. Detection of movement intention from single-trial movement-related cortical potentials. J. Neural Eng. 2011, 8, 066009. [CrossRef] [PubMed]

16. Xu, R.; Jiang, N.; Lin, C.; Mrachacz-Kersting, N.; Dremstrup, K.; Farina, D. Enhanced Low-Latency Detection of Motor Intention From EEG for Closed-Loop Brain-Computer Interface Applications. IEEE Trans. Biomed. Eng. 2014, 61, 288-296. [CrossRef] [PubMed]

17. Jochumsen, M.; Niazi, I.K.; Mrachacz-Kersting, N.; Farina, D.; Dremstrup, K. Detection and classification of movement-related cortical potentials associated with task force and speed. J. Neural Eng. 2013, 10, 056015. [CrossRef] [PubMed]

18. Lew, E.; Chavarriaga, R.; Silvoni, S.; Millán, J.D.R. Detection of self-paced reaching movement intention from EEG signals. Front. Neuroeng. 2012, 5, 13. [CrossRef] [PubMed]

19. Ofner, P.; Schwarz, A.; Pereira, J.; Müller-Putz, G.R. Upper limb movements can be decoded from the time-domain of low-frequency EEG. PLoS ONE 2017, 12, e0182578. [CrossRef] [PubMed]

20. Vukelić, M.; Gharabaghi, A. Oscillatory entrainment of the motor cortical network during motor imagery is modulated by the feedback modality. Neuroimage 2015, 111, 1-11. [CrossRef] [PubMed]

21. Kamavuako, E.N.; Jochumsen, M.; Niazi, I.K.; Dremstrup, K. Comparison of Features for Movement Prediction from Single-Trial Movement-Related Cortical Potentials in Healthy Subjects and Stroke Patients. Comput. Intell. Neurosci. 2015, 2015, 858015. [CrossRef] [PubMed]

22. Jochumsen, M.; Khan Niazi, I.; Taylor, D.; Farina, D.; Dremstrup, K. Detecting and classifying movement-related cortical potentials associated with hand movements in healthy subjects and stroke patients from single-electrode, single-trial EEG. J. Neural Eng. 2015, 12, 056013. [CrossRef] [PubMed] 
23. Karimi, F.; Kofman, J.; Mrachacz-Kersting, N.; Farina, D.; Jiang, N. Detection of Movement Related Cortical Potentials from EEG Using Constrained ICA for Brain-Computer Interface Applications. Front. Neurosci. 2017, 11, 356. [CrossRef] [PubMed]

24. Jin, Z.; Zhou, G.; Gao, D.; Zhang, Y. EEG classification using sparse Bayesian extreme learning machine for brain-computer interface. Neural Comput. Appl. 2018, 1-9. [CrossRef]

25. Ma, J.; Zhang, Y.; Cichocki, A.; Matsuno, F. A Novel EOG/EEG Hybrid Human-Machine Interface Adopting Eye Movements and ERPs: Application to Robot Control. IEEE Trans. Biomed. Eng. 2015, 62, 876-889. [CrossRef] [PubMed]

26. Zhang, Y.; Nam, C.S.; Zhou, G.; Jin, J.; Wang, X.; Cichocki, A. Temporally Constrained Sparse Group Spatial Patterns for Motor Imagery BCI. IEEE Trans. Cybern. 2018, 1-11. [CrossRef] [PubMed]

27. Zhang, Y.; Zhou, G.; Jin, J.; Zhao, Q.; Wang, X.; Cichocki, A. Sparse Bayesian Classification of EEG for Brain-Computer Interface. IEEE Trans. Neural Netw. Learn. Syst. 2016, 27, 2256-2267. [CrossRef] [PubMed]

28. Bergquist, A.J.; Clair, J.M.; Collins, D.F. Motor unit recruitment when neuromuscular electrical stimulation is applied over a nerve trunk compared with a muscle belly: Triceps surae. J. Appl. Physiol. 2011, 110, 627-637. [CrossRef] [PubMed]

29. Ibáñez, J.; Serrano, J.I.; del Castillo, M.D.; Monge-Pereira, E.; Molina-Rueda, F.; Alguacil-Diego, I.; Pons, J.L. Detection of the onset of upper-limb movements based on the combined analysis of changes in the sensorimotor rhythms and slow cortical potentials. J. Neural Eng. 2014, 11, 056009. [CrossRef] [PubMed]

30. Jochumsen, M.; Niazi, I.K.; Nedergaard, R.W.; Navid, M.S.; Dremstrup, K. Effect of subject training on a movement-related cortical potential-based brain-computer interface. Biomed. Signal Process. Control 2018, 41, 63-68. [CrossRef]

31. Corbet, T.; Iturrate, I.; Pereira, M.; Perdikis, S.; Millán, J.D.R. Sensory threshold neuromuscular electrical stimulation fosters motor imagery performance. Neuroimage 2018, 176, 268-276. [CrossRef] [PubMed]

32. Daly, J.J.; Cheng, R.; Rogers, J.; Litinas, K.; Hrovat, K.; Dohring, M. Feasibility of a New Application of Noninvasive Brain Computer Interface (BCI): A Case Study of Training for Recovery of Volitional Motor Control After Stroke. J. Neurol. Phys. Ther. 2009, 33, 203-211. [CrossRef] [PubMed]

33. Jochumsen, M.; Niazi, I.K.; Signal, N.; Nedergaard, R.W.; Holt, K.; Haavik, H.; Taylor, D. Pairing Voluntary Movement and Muscle-Located Electrical Stimulation Increases Cortical Excitability. Front. Hum. Neurosci. 2016, 10, 482. [CrossRef] [PubMed]

34. Mrachacz-Kersting, N.; Voigt, M.; Stevenson, A.J.T.; Aliakbaryhosseinabadi, S.; Jiang, N.; Dremstrup, K.; Farina, D. The effect of type of afferent feedback timed with motor imagery on the induction of cortical plasticity. Brain Res. 2017, 1674, 91-100. [CrossRef] [PubMed]

35. Khaslavskaia, S.; Sinkjaer, T. Motor cortex excitability following repetitive electrical stimulation of the common peroneal nerve depends on the voluntary drive. Exp. Brain Res. 2005, 162, 497-502. [CrossRef] [PubMed]

36. Barsi, G.I.; Popovic, D.B.; Tarkka, I.M.; Sinkjær, T.; Grey, M.J. Cortical excitability changes following grasping exercise augmented with electrical stimulation. Exp. Brain Res. 2008, 191, 57-66. [CrossRef] [PubMed]

37. Taylor, L.; Lewis, G.N.; Taylor, D. Short-term Effects of Electrical Stimulation and Voluntary Activity on Corticomotor Excitability in Healthy Individuals and People With Stroke. J. Clin. Neurophysiol. 2012, 29, 237-243. [CrossRef] [PubMed]

38. Kaneko, F.; Hayami, T.; Aoyama, T.; Kizuka, T. Motor imagery and electrical stimulation reproduce corticospinal excitability at levels similar to voluntary muscle contraction. J. Neuroeng. Rehabil. 2014, 11, 94. [CrossRef] [PubMed]

39. Rossi, S.; Hallett, M.; Rossini, P.M.; Pascual-Leone, A. Safety of TMS Consensus Group Safety, ethical considerations, and application guidelines for the use of transcranial magnetic stimulation in clinical practice and research. Clin. Neurophysiol. 2009, 120, 2008-2039. [CrossRef] [PubMed]

40. Toumi, A.; Leteneur, S.; Gillet, C.; Debril, J.-F.; Decoufour, N.; Barbier, F.; Jakobi, J.M.; Simoneau-Buessinger, E. Enhanced precision of ankle torque measure with an open-unit dynamometer mounted with a 3D force-torque sensor. Eur. J. Appl. Physiol. 2015, 115, 2303-2310. [CrossRef] [PubMed]

41. Arceo, J.C.; Lauber, J.; Robinault, L.; Paganelli, S.; Jochumsen, M.; Niazi, I.K.; Simoneau, E.; Cremoux, S. Modeling and Control of Rehabilitation Robotic Device: motoBOTTE. In Proceedings of the International Conference on Neurorehabilitation, Pisa, Italy, 16-20 October 2018. 
42. Arceo, J.C.; Lauber, J.; Simoneau, E.; Cremoux, S. Nonlinear controller design for robotic assistive therapy. In Proceedings of the 2018 IEEE/RSJ International Conference on Intelligent Robots and Systems, Madrid, Spain, 1-5 October 2018.

43. Kunz, C.U.; Stallard, N.; Parsons, N.; Todd, S.; Friede, T. Blinded versus unblinded estimation of a correlation coefficient to inform interim design adaptations. Biom. J. 2017, 59, 344-357. [CrossRef] [PubMed]

44. Bates, D.; Mächler, M.; Bolker, B.; Walker, S. Fitting Linear Mixed-Effects Models using lme4. J. Stat. Softw. 2014. [CrossRef]

45. Jaeger, B.C. r2glmm: Computes R Squared for Mixed (Multilevel) Models. Available online: https:/ /CRAN. R-project.org $/$ package $=$ r2glmm (accessed on 20 October 2018).

46. Twisk, J.; Bosman, L.; Hoekstra, T.; Rijnhart, J.; Welten, M.; Heymans, M. Different ways to estimate treatment effects in randomised controlled trials. Contemp. Clin. Trials Commun. 2018, 10, 80-85. [CrossRef]

47. Ridding, M.C.; Ziemann, U. Determinants of the induction of cortical plasticity by non-invasive brain stimulation in healthy subjects. J. Physiol. 2010, 588, 2291-2304. [CrossRef] [PubMed]

48. Sinkjaer, T.; Andersen, J.B.; Ladouceur, M.; Christensen, L.O.; Nielsen, J.B. Major role for sensory feedback in soleus EMG activity in the stance phase of walking in man. J. Physiol. 2000, 523, 817-827. [CrossRef] [PubMed]

49. Nielsen, J.B.; Sinkjaer, T. Afferent feedback in the control of human gait. J. Electromyogr. Kinesiol. 2002, 12, 213-217. [CrossRef]

50. Rosenkranz, K.; Rothwell, J.C. Differences between the effects of three plasticity inducing protocols on the organization of the human motor cortex. Eur. J. Neurosci. 2006, 23, 822-829. [CrossRef] [PubMed]

51. Mrachacz-Kersting, N.; Fong, M.; Murphy, B.A.; Sinkjær, T. Changes in Excitability of the Cortical Projections to the Human Tibialis Anterior After Paired Associative Stimulation. J. Neurophysiol. 2007, 97, 1951-1958. [CrossRef] [PubMed]

52. Petersen, N.; Christensen, L.O.; Morita, H.; Sinkjaer, T.; Nielsen, J. Evidence that a transcortical pathway contributes to stretch reflexes in the tibialis anterior muscle in man. J. Physiol. 1998, 512, 267-276. [CrossRef] [PubMed]

53. Collins, D.F. Central Contributions to Contractions Evoked by Tetanic Neuromuscular Electrical Stimulation. Exerc. Sport Sci. Rev. 2007, 35, 102-109. [CrossRef] [PubMed]

54. Suppa, A.; Quartarone, A.; Siebner, H.; Chen, R.; Di Lazzaro, V.; Del Giudice, P.; Paulus, W.; Rothwell, J.C.; Ziemann, U.; Classen, J. The associative brain at work: Evidence from paired associative stimulation studies in humans. Clin. Neurophysiol. 2017, 128, 2140-2164. [CrossRef] [PubMed]

55. Olsen, S.; Signal, N.; Niazi, I.K.; Christensen, T.; Jochumsen, M.; Taylor, D. Paired Associative Stimulation Delivered by Pairing Movement-Related Cortical Potentials With Peripheral Electrical Stimulation: An Investigation of the Duration of Neuromodulatory Effects. Neuromodul. Technol. Neural Interface 2018, 21, 362-367. [CrossRef] [PubMed]

56. Biasiucci, A.; Leeb, R.; Iturrate, I.; Perdikis, S.; Al-Khodairy, A.; Corbet, T.; Schnider, A.; Schmidlin, T.; Zhang, H.; Bassolino, M.; et al. Brain-actuated functional electrical stimulation elicits lasting arm motor recovery after stroke. Nat. Commun. 2018, 9, 2421. [CrossRef] [PubMed]

57. Ramos-Murguialday, A.; Broetz, D.; Rea, M.; Läer, L.; Yilmaz, Ö.; Brasil, F.L.; Liberati, G.; Curado, M.R.; Garcia-Cossio, E.; Vyziotis, A.; et al. Brain-machine interface in chronic stroke rehabilitation: A controlled study. Ann. Neurol. 2013, 74, 100-108. [CrossRef] [PubMed]

(C) 2018 by the authors. Licensee MDPI, Basel, Switzerland. This article is an open access article distributed under the terms and conditions of the Creative Commons Attribution (CC BY) license (http://creativecommons.org/licenses/by/4.0/). 